\title{
Are Consumer Perceptions Of Retailers Aligned With Retail Store Positioning?
}

Gladys Torres-Baumgarten, (E-mail: gbaumgar@kean.edu), Kean University

Veysel Yucetepe, (E-mail: vyucetep@kean.edu), Kean University

\begin{abstract}
This empirical study extends previous store image research by using consumer perceptions of store image to determine whether these perceptions are aligned with retailers' intended positioning.
\end{abstract}

\section{INTRODUCTION}

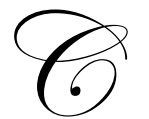

ompetition in the retailing sector continues to intensify, with each retailer constantly striving to maintain or increase market share. The battle for market share requires that each retailer have a clear positioning strategy that effectively differentiates individual retailers from the rest of the competitive field. While the positioning distinctions are clear to retailers, what is often not known is whether consumers recognize the same distinctions. The retail industry is of interest to marketing academicians and practitioners alike because of the significant role it plays in the economy:

- $\quad$ The U.S. retailing industry generates over $\$ 3.8$ trillion in sales per year (or $\$ 4.2$ trillion if food sales were included) (http://retailindustry.about.com).

- It is the second largest industry in the U.S. in terms of the number of employees and number of establishments.

- $\quad$ The dynamic competitive environment of the past decade has seen (and continues to see) major retail stores and chains file for bankruptcy, foreclose, or merge.

- $\quad$ Specialty retailers, mega-stores, and non-store retailing (e.g. catalogs and online shopping) have also experienced significant growth in recent years.

This highly contested marketplace underscores the need for individual retailers to establish meaningful distinctions that will help its target market distinguish that retailer from other competitors. However, clear retailer positioning may not always translate to clear distinctions among retailers from the consumer's perspective, and failure to align consumer perceptions with retail positioning will result in ineffective and inefficient use of the retailer's marketing expenditures. Therefore, comprehending consumers' understanding of retailer positioning should be a priority among retailers in order to grasp whether marketing expenditures are being used effectively. Recognizing that retailer marketing research budgets may be limited, and that studies may be conducted for other purposes (including gauging advertising communication, promotional effectiveness, etc.), we argue that retailers should also consider a more basic question, i.e., are consumer perceptions aligned with our intended retail store positioning?

\section{STUDY OBJECTIVES}

This study seeks to 1) analyze the retail store competitive market structure with the aid of hierarchical clustering techniques, a technique that to date has not been applied to the retailing sector, but that is highly applicable in the study of consumer perceptions; and 2) compare whether consumer perceptions of retail stores are aligned with the retail store's positioning. These issues are of particular interest to retailers who compete daily with other retailers for coveted market share. Yet, competition (and hence, the need for clear differentiation) is even more intense in certain segments of the retailing industry. One of the most sought after segments in the retailing 
industry is the young adult segment (18 -24 year olds) that tends to spend heavily on certain product categories, including apparel, music, and electronics. To facilitate understanding of retailer perceptions, we felt that it was important to focus on retailers that are often patronized by a select market segment and for a particular product category. Hence, this study looks at the 18-24 year old market segment, a highly attractive retailing segment; and the category of interest is apparel since this segment spends heavily on clothing and they demonstrate a high level of involvement for it. By narrowing the target market and the category, it is expected that a clearer understanding of consumer perceptions' alignment with retailer positioning will be obtained. In particular, consumers' similarity judgments on two key variables that influence store image are used to derive the competitive market structure of select retail stores. The two key variables are merchandise quality and service quality. (The rationale for selecting these two variables is discussed further in the literature review.)

It is expected that this paper will contribute to the retailing literature in two significant ways:

- $\quad$ This paper will demonstrate that the alignment of the retailer's intended store positioning with consumer perceptions is not always what retailers presume it to be. Realizing that consumer perceptions differ from retailer positioning may lead to further refinements in the retailer's marketing strategy, and ultimately strengthen their position in the marketplace vis-à-vis the competition.

- $\quad$ This paper will demonstrate that similarity judgments, used as input for the clustering analytic techniques, are appealing from a methodological standpoint because it enables consumers to recreate, in their minds, a situation that is representative of retail store decisions in the marketplace - in addition to being convenient and simple for respondents.

\section{LITERATURE REVIEW}

\section{Retail Store Image Literature}

A review of the literature on store image research revealed that it is quite extensive (Doyle \& Fenwick 1974; Jain \& Etgar 1976: King \& Ring 1980; Chowdhury et al 1998), with some research efforts having attempted to explore the evolution of store image formation (Mazursky and Jacoby 1986); and others seeking to conduct a meta-analysis of retail patronage studies (Pan \& Zinkhan 2006). However, the existing literature did not reveal any prior studies where clustering techniques had been used to study consumers' perceptions of store image.

Consumers' perception of store image is based, in part, on functional qualities that the store may possess, and by other, less tangible or psychological attributes (Lindquist 1974). Lindquist analyzed over 20 studies dealing with store image formation and identified 35 different aspects that influence store image formation. These were grouped into nine broad categories, including: merchandise, service, clientele, physical facilities, convenience, promotion, store atmosphere, institutional attributes, and post-transaction satisfaction.

Mazursky and Jacoby (1986) conducted a similar analysis and verified that "merchandise related aspects" (such as quality, pricing and assortment), and "service related aspects" (such as quality in general and salesperson's service) are among the most important components of store image. A 1994 study by Baker, Grewal and Parasuraman confirmed that "the store image literature suggests there are linkages between merchandise and service quality, and store image." A later study by Baker, Grewal and Voss (2002) also confirmed that service quality was a key determinant of store image. Given the prevalence in the literature of merchandise and service as two key determinants in the formation of store image, these two attributes were selected for this present study to gauge consumer's perceptions of retail stores. These attributes were incorporated in this study by obtaining consumer similarity judgments on retailers" "service quality" and "merchandise quality".

The clustering of retail stores based on these two attributes will yield a better understanding of competition within the retailing industry. This is of interest from a strategic marketing standpoint in that many off-price retailers carry the same quality merchandise as other, higher priced retailers (namely, department stores and specialty stores). In previous years, competition within the retail sector was more clearly delineated in that department stores tended to compete with other department stores; and in general, stores of a specific type tended to compete with like stores. 
In reality, these distinctions (at least with regards to merchandise quality) may not be as clear today since off-price retailers often carry the same merchandise as specialty and department stores. No longer can the competition be viewed as narrowly - merely by store type - as it had been in the past for purposes of marketing strategy development.

Off-price retailers strive to convince consumers that their product quality is comparable to that of department stores. This study will enable us to confirm whether consumer perceptions of product quality will also yield information that would be of strategic interest to retailers.

\section{Brand Equity Literature}

One novel way to view store image might be to draw from the brand equity literature. In particular, one could claim that store equity could be analogous to brand equity. The literature on brand equity reveals that there are "brand-specific" associations. These are defined as "an attribute or benefit that differentiates a brand from competing brands" (MacInnis and Nakamoto 1990; Broniarczyck \& Alba 1994). Extending this rationale to stores, one could argue that "store-specific associations" also exist and that these consist of those "attributes or benefits that differentiate a store from a competing store". Such "store specific associations" could include benefits as service, atmospherics, product assortment, locations, etc. Keller (2003) has stated that retailer equity is similar to familiarity with the store name, and that consumers use this to make inferences about the retailers' merchandise and service offerings.

Myers and Alpert (1968) found that when these brand associations are linked to important benefits sought by customers, they may motivate a purchase, and therefore, can ensure the product's marketing success. As Myers and Alpert indicated, these brand-related benefits are frequently communicated and reinforced through the marketer's promotional efforts aimed at consumers. Thus, "store-specific associations" also exist and researchers ought to explore these store effects and determine how they influence store affect, and ultimately patronage motives. Once the underlying store effects are identified, then this information can be used to develop the stores' advertising and promotional strategies. It is clear that stores promote their positioning in their advertising, but is that positioning consistent with consumer's "store-specific associations"?

\section{METHODOLOGY}

The consumer segment of interest for many retailers - and for our study - is 18-24 year olds. As a result, undergraduate university students were used as respondents in this study. While the authors recognize the limitations of a student sample (Fern \& Monroe 1996), it was deemed justified here because the sample is more than just a convenience sample; i.e. they represent the population of interest.

In order to identify the retail stores that are of interest to this coveted age group, students were asked to provide a list of the retailers that they tended to patronize when buying apparel. A total of eleven stores was generated (based on the frequency with which they were cited) and selected for inclusion in a survey instrument. A questionnaire with 57 paired comparisons of retail stores was devised (55 paired comparisons, plus two repeated pairs to test for reliability) and randomly distributed to two groups, comparable in age to gauge consumer perceptions of retail stores. One group was asked to gauge the retail stores' similarity with regards to merchandise quality and the other, with regards to service quality.

A total of 39 usable questionnaires were used in the analysis (22, or $56 \%$ men/ 17 , or $42 \%$ women). Clustering analytic techniques were used to determine how similar consumers perceived the various retailers in the study to be with regards to two key determinants of store image: merchandise and service quality. Retailer positioning was determined by the authors using secondary sources, such as articles in business journals, and retailing industry websites. 


\section{FINDINGS}

\section{Merchandise Quality}

When consumers were asked about merchandise quality, clusters tended to form initially by store type, i.e., specialty stores such as Hollister and Abercrombie \& Fitch (A\&F from hereon) tended to cluster first, and were soon joined by American Eagle. The next cluster to form consisted of Macys and J.C. Penneys, suggesting that department store clothing - at least for these two retailers - is perceived to be of similar quality. The next cluster to form consisted of Kohl's and Marshalls, i.e. a mass merchandiser and an off-price retailer, respectively. This may present a positioning challenge for Marshalls in particular, since their positioning is based on the premise that they sell "designer clothing for less". Nevertheless, this desirable consumer segment perceives Marshalls merchandise quality to be similar to that of a mass merchandiser, albeit a more upmarket mass merchandiser than say, a Walmart or Kmart. The next pair to cluster was Aerospostale and Old Navy; thus while Aeropostale is a specialty store, the merchandise quality is perceived to be similar to that found in Old Navy, the less expensive retailer under the Gap Corporation.

The Gap subsequently joined the Hollister, A\&F and American Eagle cluster. This suggests that consumers perceive the merchandise quality of specialty stores as being similar. The Marshalls \& Kohl's cluster is then joined by Target, also an upmarket mass merchandiser. The next cluster is formed by the union of The Gap with the Aeropostale and Old Navy cluster; and ultimately, these stores cluster with the A\&F, American Eagle and Hollister cluster. This larger cluster brings together all specialty stores, yet the earlier clusters seemed to be grouped by price point since American Eagle/Hollister/and A\&F are premium priced specialty stores, while Gap and Aeropostale are lower priced specialty stores. This clustering indicates that respondents are informed consumers that appear to be well aware of price point differences.

Figure 1. Dendrogram of Merchandise Quality

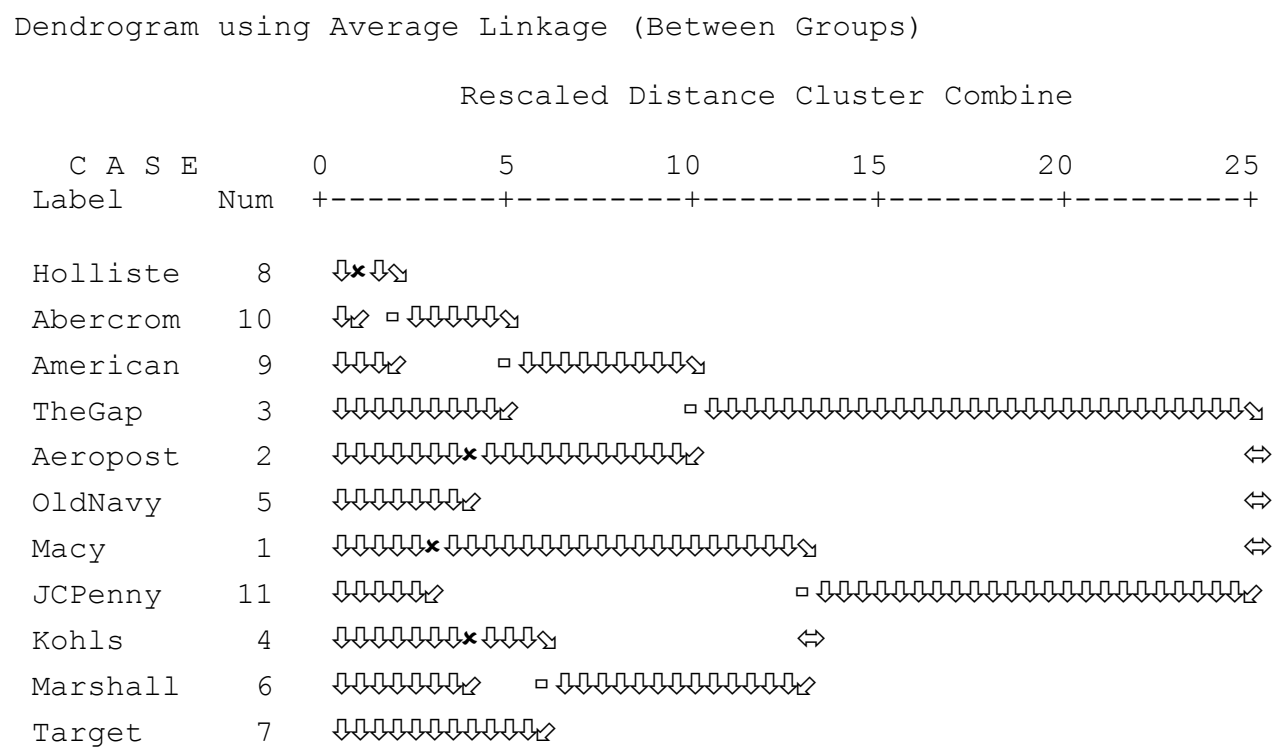




\section{Service Quality}

The first cluster to form is American Eagle and A\&F, and shortly thereafter, these are joined by Hollister. This first cluster formation was also the first cluster for merchandise quality so consumers appear to view these three specialty retailers as very similar in several respects. The next most similar cluster is Macys and JC Penney. Once again, consumers appear to judge the service quality in these two department stores as very similar. The American Eagle/A\&F/Hollister cluster is soon joined by Aeropostale. This suggests that even though Aeropsotale's merchandise quality was in line with Old Navy's (merchandise quality), that in terms of service quality, they actually cluster quite readily with the upscale specialty retailers. These findings suggest that Aeropostale could be doing more to enhance consumer perceptions of its merchandise quality, especially since consumers already think its service quality is at par with the more upscale specialty retailers. The Gap and Old Navy form the next cluster, suggesting that The Gap Corporation could do more to delineate the differences between The Gap, its main retail brand and Old Navy, its lower priced retail alternative.

The next cluster to form was the union of the Kohl's/Marshalls cluster with Target. Stores that tend to be larger than specialty stores appear to be judged similarly by consumers in terms of service quality. This suggests that more might be done to upgrade service quality in these stores.

In the end, The Gap/ Old Navy cluster joined the initial cluster formed by American Eagle/A\&F/ Hollister. Since this is the last cluster to form, respondents felt that these were the stores that differed the most with regards to service quality. This suggests that The Gap and Old Navy should implement some service improvement initiatives to enhance consumer perceptions of service quality, a key component of store image.

Figure 2. Dendrogram of Service Quality

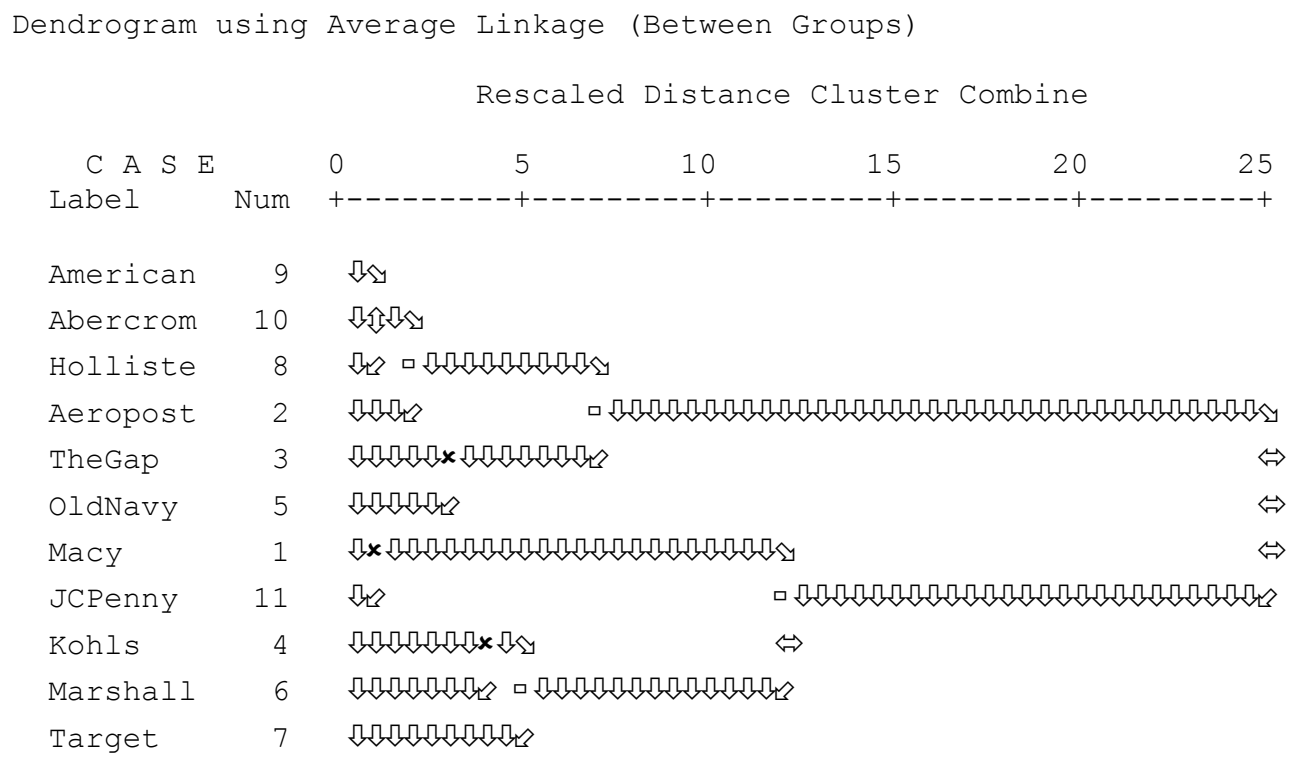




\section{CONCLUSION}

From a methodological standpoint, this study showed that similarity judgments represent a realistic way to test consumers' decision-making behavior when they think about going shopping for apparel. Consumers are likely to have a consideration set of retail store brands and are likely to think which ones to patronize in terms of how similar they are. This was an exploratory study to determine the market structure of the retailing industry using similarity data and clustering techniques. The methodology was shown to be effective in determining the market structure of the specific retailers in the study and since the sample population was the same as the retailers' target market, the strategic findings that were drawn are applicable in the marketplace. Future research in this area could incorporate the consumption context (i.e. situational factors) since situational factors are likely to be a strong determinant of consumer choice decisions when selecting a retailer. For example, a given consumer may opt to buy in one store when looking for a gift, but may shop at a store with a very different profile when searching for products for his/her own consumption. It is recommended in a case such as this that overlapping clustering techniques be used in this case to allow for the simultaneous inclusion of the objects under study in several clusters.

\section{REFERENCES}

1. Baker, J., Grewal, D., \& Parasuraman, A. (1994). The influence of store environment on quality inferences and store image. Journal of the Academy of Marketing Science. 22(4): 328-339.

2. Baker, J., Grewal, D., \& Voss, G.B. (2002). The influence of multiple store environment cues on perceived merchandise value and patronage intentions. Journal of Marketing, 66 (2):120-141.

3. Broniarczyk, S.M., \& Alba, J. (1994). The importance of the brand in brand extensions. Journal of Marketing Research. 31: 214-228.

4. Chowdhury, J., Reardon, J. \& Srivastava, J. (1998). Alternative modes of measuring store image: an empirical assessment of structured versus unstructured measures. Journal of Marketing Theory and Practice 6 (2): 72-86.

5. Doyle, P. \& Fenwick, I. (1974). How store images affect shopping habits in grocery chains. Journal of Retailing. 50: 39-52.

6. Fern, E. F. \& Monroe, K.B. (September, 1996). Effect size estimates: issues and problems in interpretation. Journal of Consumer Research. 23: 89-115.

7. http: //retailindustry.about.com

8. Jain, A.K. \& Etgar, M. (1976). Measuring store image through multidimensional scaling of free response data. Journal of Retailing. 52 (4): 61-70.

9. Keller, K. (2003). Building, measuring, and managing brand equity, Upper Saddle River, NJ: Prentice Hall.

10. King, C.W. \& Ring, L.J. (1980). Market positioning across retail fashion institutions: A comparative analysis of store types. Journal of Retailing. 56:37-55.

11. Lindquist, J.D. (1974). Meaning of image. Journal of Retailing. 50 (4): 29-40.

12. MacInnis, D. \& Nakamoto, K. (1990). Examining factors that influence the perceived goodness of brand extensions. Working paper \#54. Karl Eller Graduate School of Management. University of Arizona.

13. Mazursky, D. \& Jacoby, J. (1986). Exploring the development of store images. Journal of Retailing. 62 (2): 145-65.

14. Pan, Y. \& Zinkhan, G. (2006). Determinants of retail store patronage: A meta-analytic perspective. Journal of Retailing. 82 (3): $229-243$. 